\title{
Creep Crack Initiation and Growth Behavior for Ni-Base Superalloys*
}

\author{
Yoshiko NAGUMO**, A. Toshimitsu YOKOBORI, Jr.**, Ryuji SUGIURA**, \\ Go OZEKI** and Takashi MATSUZAKI** \\ **Department of Nanomechanics, Tohoku University \\ 6-6-01, Aramaki-aza-aoba, Aoba-ku, Sendai-city, Japan \\ E-mail: nagumo@md.mech.tohoku.ac.jp
}

\begin{abstract}
The structural components which are used in high temperature gas turbines have various shapes which may cause the notch effect. Moreover, the site of stress concentration might have the heterogeneous microstructural distribution. Therefore, it is necessary to clarify the creep fracture mechanism for these materials in order to predict the life of creep fracture with high degree of accuracy. In this study, the creep crack growth tests were performed using in-situ observational testing machine with microscope to observe the creep damage formation and creep crack growth behavior. The materials used are polycrystalline Ni-base superalloy IN100 and directionally solidified Ni-base superalloy CM247LC which were developed for jet engine turbine blades and gas turbine blades in electric power plants, respectively. The microstructural observation of the test specimens was also conducted using FE-SEM/EBSD. Additionally, the analyses of two-dimensional elastic-plastic creep finite element using designed methods were conducted to understand the effect of microstructural distribution on creep damage formation. The experimental and analytical results showed that it is important to determine the creep crack initiation and early crack growth to predict the life of creep fracture and it is indicated that the highly accurate prediction of creep fracture life could be realized by measuring notch opening displacement proposed as the RNOD characteristic.
\end{abstract}

Key words: Ni-Base Superalloy, IN100, CM247LC, Creep Damage, Crack Initiation, Crack Growth, Finite Element Method

\section{Introduction}

Researches on heat-resistant materials such as Ni-base superalloys for high temperature components have been progressed remarkably. Ni-base superalloys used for jet engines and gas turbine blades have high creep resistance due to the strengthening microstructure such as $\gamma^{\prime}$ precipitates. When these materials are practically used as the components of structures, cracks may occur due to the external loading, which results in failure. The prediction of the creep fracture life for these materials are developed based on the experimental results which were conducted by using smooth specimens, focused on the degradation of the $\gamma^{\prime}$ structure and the precipitates such as carbide precipitation ${ }^{1)}$. However, the structural components which are used in high temperature components have various shapes which may cause the notch effect. The site of stress concentration might have the heterogeneous microstructural distribution, which resulted in the occurrence of

*Received 1 Dec., 2011 (No. 11-0745) [DOI: 10.1299/jmmp.6.610]

Copyright (C) 2012 by JSME 
unpredictable fracture. Additionally, it is reported that the creep crack growth behavior of these materials are complicated due to the strengthening microstructure ${ }^{2)}$. To predict the creep fracture life of Ni-base superalloy, the creep crack growth rate has been correlated with the stress intensity factor $K$ or $C^{*}$ parameter $^{3-6)}, \dot{\delta}^{7-9)}$, and $Q^{*}$ parameter $^{10,11)}$. Moreover, the damage mechanics ${ }^{12)}$ was proposed to characterize the creep deformation or crack initiation $^{13)}$. However, the difficulties of applications of such parameters for creep brittle materials were indicated by the previous papers ${ }^{11)}$.

In this study, to clarify the relationship between creep crack growth behavior and the heterogeneous microstructural distribution around the notch tip for estimating the appropriate fracture mechanics variation for the prediction of creep crack growth life of creep brittle material, creep crack growth tests for Ni-base superalloys were conducted. Additionally, the analyses of two-dimensional elastic-plastic creep finite element using the designed method were conducted to understand the effect of strengthening mechanism on creep damage formation behavior. Finally, the discussion was conducted to establish the precise law of creep fracture life of Ni-base superalloys.

\section{Creep crack initiation and growth test}

\subsection{Experimental procedures}

The materials used are polycrystalline Ni-base superalloy IN100 and directionally solidified Ni-base superalloy CM247LC which were developed for the jet engine turbine blade and the gas turbine blade for electric power plants, respectively. The chemical compositions and mechanical properties are shown in Tables 1 and 2 , respectively ${ }^{14)}$. The specimen used is a Double Edge Notched (DEN) specimen which has V notch in both side of the parallel site of the specimen, as shown in Fig. 1. The creep crack growth tests were performed using in-situ observational testing machine with microscope ${ }^{15}$ to observe the creep damage formation and creep crack growth behavior, as shown in Fig. 2. The tests conditions are shown in Table 3. After the tests, the observation of material microstructure was conducted using FE-SEM/EBSD on the test specimens.

Table 1 Chemical compositions of IN100 and CM247LC in wt \%

\begin{tabular}{|c|c|c|c|c|c|c|c|c|c|c|}
\hline \multirow{2}{*}{ IN100 } & C & $\mathrm{Cr}$ & Co & Mo & $\mathrm{Ti}$ & Al & B & $\mathrm{Zr}$ & V & $\mathrm{Ni}$ \\
\hline & 0.18 & 10.00 & 15.00 & 3.00 & 4.70 & 5.50 & 0.01 & 0.06 & 0.90 & Bal. \\
\hline \multirow{4}{*}{ CM247LC } & C & $\mathbf{S i}$ & Mn & $\mathbf{P}$ & $\mathbf{s}$ & $\mathrm{Cr}$ & Co & Mo & $\mathrm{Zr}$ & v \\
\hline & $\begin{array}{l}0.05- \\
0.09\end{array}$ & $<0.03$ & $<0.10$ & $<0.015$ & $<0.015$ & $\begin{array}{l}8.00- \\
8.60\end{array}$ & $\begin{array}{l}9.00- \\
9.50\end{array}$ & $\begin{array}{l}0.40- \\
0.60\end{array}$ & $\begin{array}{l}0.007- \\
0.22\end{array}$ & $<0.10$ \\
\hline & $\mathrm{Ti}$ & Al & $\mathrm{Fe}$ & B & w & $\mathrm{Nb}$ & $\mathrm{Hf}$ & $\mathrm{Ta}$ & $\mathrm{Ni}$ & \\
\hline & $\begin{array}{l}0.60- \\
0.90\end{array}$ & $\begin{array}{l}5.30- \\
5.70\end{array}$ & $<0.25$ & $\begin{array}{l}0.01- \\
0.02\end{array}$ & $\begin{array}{l}9.30- \\
9.70\end{array}$ & $<0.10$ & $\begin{array}{l}1.30- \\
1.60\end{array}$ & $\begin{array}{l}2.80- \\
3.30\end{array}$ & Bal. & \\
\hline
\end{tabular}


Table 2 Mechanical properties of IN100 and CM247LC

\begin{tabular}{|c|c|c|c|c|}
\hline \multirow{4}{*}{ IN100 } & $\begin{array}{c}\text { Temperature } \\
{\left[{ }^{\circ} \mathrm{C}\right]}\end{array}$ & $\begin{array}{c}\text { Tensile stress } \\
{[\mathrm{MPa}]}\end{array}$ & $\begin{array}{c}\mathbf{0 . 2 \%} \text { proof stress } \\
{[\mathrm{MPa}]}\end{array}$ & $\begin{array}{c}\text { Elongation } \\
{[\%]}\end{array}$ \\
\hline \multirow{3}{*}{25} & 918 & 781 & 5.9 \\
\cline { 2 - 5 } & 732 & 1000 & 787 & 8.0 \\
\cline { 2 - 5 } & 850 & 1026 & 861 & 7.3 \\
\hline \multirow{3}{*}{ CM247LC } & 25 & 858 & 605 & 5.9 \\
\cline { 2 - 5 } & 750 & 1152 & 984 & 10.2 \\
\cline { 2 - 5 } & 850 & 870 & 794 & 8.1 \\
\hline
\end{tabular}

Table 3 Testing conditions.

\begin{tabular}{cccc}
\hline \multirow{4}{*}{ IN100 } & $\begin{array}{c}\text { Temperature } \\
\left({ }^{\circ} \mathrm{C}\right)\end{array}$ & $\begin{array}{c}\text { Stress } \\
(\mathrm{MPa})\end{array}$ & $\begin{array}{c}\text { Fracture time } \\
\mathrm{t}_{\mathrm{f}}(\mathrm{h})\end{array}$ \\
\cline { 2 - 4 } & 900 & 327 & 111.7 \\
\cline { 2 - 4 } & 850 & 327 & 84 \\
\hline \multirow{3}{*}{ CM247LC } & 965 & 300 & 1361 \\
\cline { 2 - 4 } & 930 & 300 & 44 \\
\cline { 2 - 4 } & 900 & 300 & 487 \\
\hline
\end{tabular}
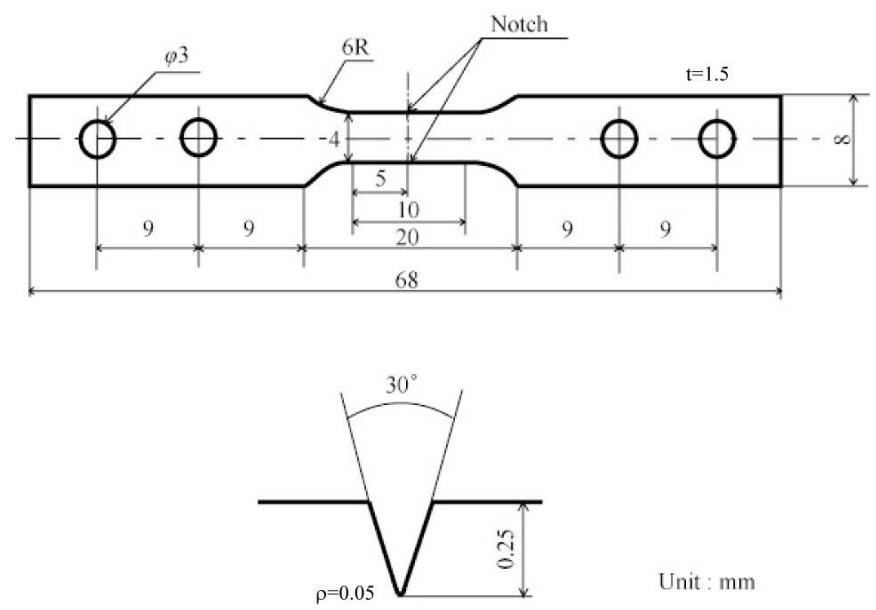

Detail of Notch part

Fig. 1 The geometry and size of a DEN specimen. 


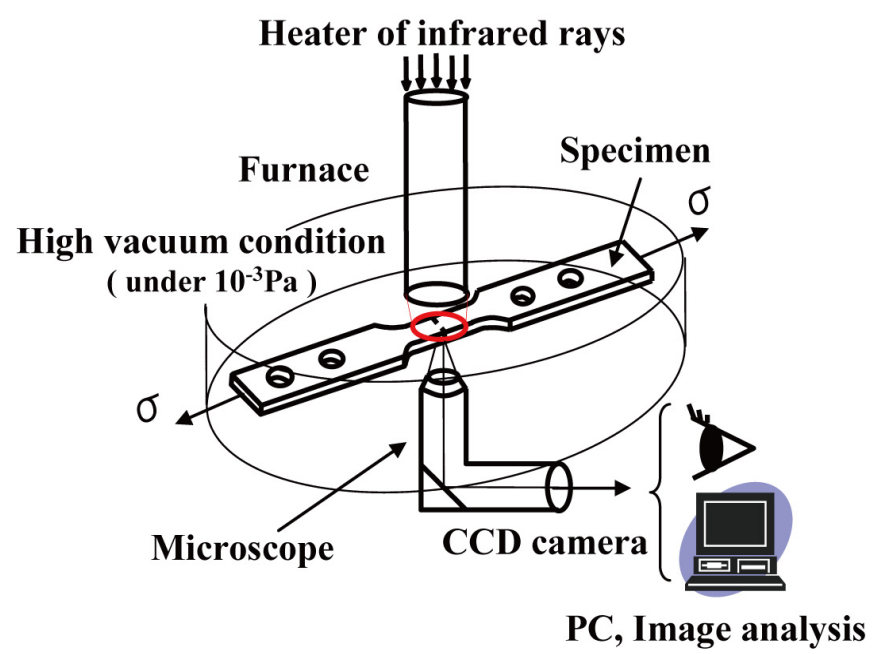

Fig. 2 High temperature creep-fatigue testing machine with in-situ observational system.

\subsection{Experimental results}

The relative notch opening displacement $(R N O D)$ was proposed as a representative quantity ${ }^{16)}$ given by

$$
R N O D=\frac{\phi-\phi_{0}}{\phi_{0}}=\frac{\Delta \phi}{\phi_{0}}
$$

where $\phi$ is the current value of notch opening displacement at the time of $t$ and $\phi_{0}$ is the initial value of notch opening displacement.

The characteristics of RNOD obtained from the creep crack growth tests of IN100 and CM247LC are shown in Fig. 3. The horizontal axis represents the normalized time $t / t_{f}$, where $t$ is the load application time and $t_{f}$ is the fracture life for each specimen. In Fig. 3, the RNOD characteristics of CM247LC show the same characteristics for all testing condition which are described by a unique curve. The RNOD characteristics of IN100 are also similar for all testing condition, however the values of RNOD for IN100 were found to decrease as compared with those of CM247LC at the final stage of creep fracture life $\left(t / t_{f}>0.6\right)$.

The in-situ observational images of the notch part of DEN specimens for IN100 and CM247LC are shown in Figs. 4 (a) and (b), respectively. Figure 4 (a) is the image for IN100 at the stage of $t / t_{f}=0.46$, in which macroscopic creep damage was not observed until the creep fracture life despite of continuous increase in the RNOD. Figure 4 (b) is the image for CM247LC that two main cracks in the direction of $45^{\circ}$ to the extended notch direction was observed, which was different from the results for IN100. Therefore, to investigate the creep damage distribution between them, the FE-SEM/EBSD analyses were conducted for the specimens of IN100 at the point of $t / t_{f}=0.46$ and CM247LC at the point of $t / t_{f}=1.0$.

The inverse pole figure (IPF) map and kernel average misorientation (KAM) map for each specimen are shown in Figs. 5 (a) and (b), respectively. In the results of IN100 as shown in Fig. 5 (a), IPF map shows the grain boundary distribution around the notch tip and KAM map shows the distribution of the local crystal misorientation of the analyzed area by colors, respectively. From these results, it is shown that the high KAM values distribute 
along the grain boundaries through the width of the specimen. It is considered that the creep damage consists of creep voids and micro cracks. For Ni-base superalloy IN100, the creep deformation was restrained and it was hard to observe creep damage and crack by in-situ observation until final fracture during the creep crack growth test. The correlation of the plastic and creep deformation with the crystal misorientation is reported ${ }^{1-5)}$. Therefore, it is indicated that the high KAM represents the existence of the creep voids. Figure 5 (b) shows the results of CM247LC. The grain boundary distributes along the loading direction and the high KAM values distribute not only along the grain boundaries but also along the intergranular dendritic microstructure.

Additionally, the creep crack growth path for IN100 and CM247LC obtained from the microscopic observation were shown in Figs. 6 (a) and (b), respectively. From Fig. 6 (a), it was shown that the creep crack grew along the high KAM value area along the grain boundaries in Fig. 5 (a). From Fig. 6 (b), for CM247LC it was observed that creep cracks grew to the direction of $45^{\circ}$ to the extended notch direction from one side of the notches, and from the other notch tip the creep crack grew to the extended notch direction despite the creep damage propagated to the direction of $45^{\circ}$ to the extended notch direction.

These two different creep damage formation and crack growth behavior of IN100 and CM247LC indicate that the microstructural distribution around the notch tip affects the creep damage formation and creep crack growth behavior. In the next section, mechanical analyses are conducted using two-dimensional elastic-plastic creep finite element method based on the designed method to find out creep damage in order to clarify the effect of the microstructural strengthening on the creep damage formation.

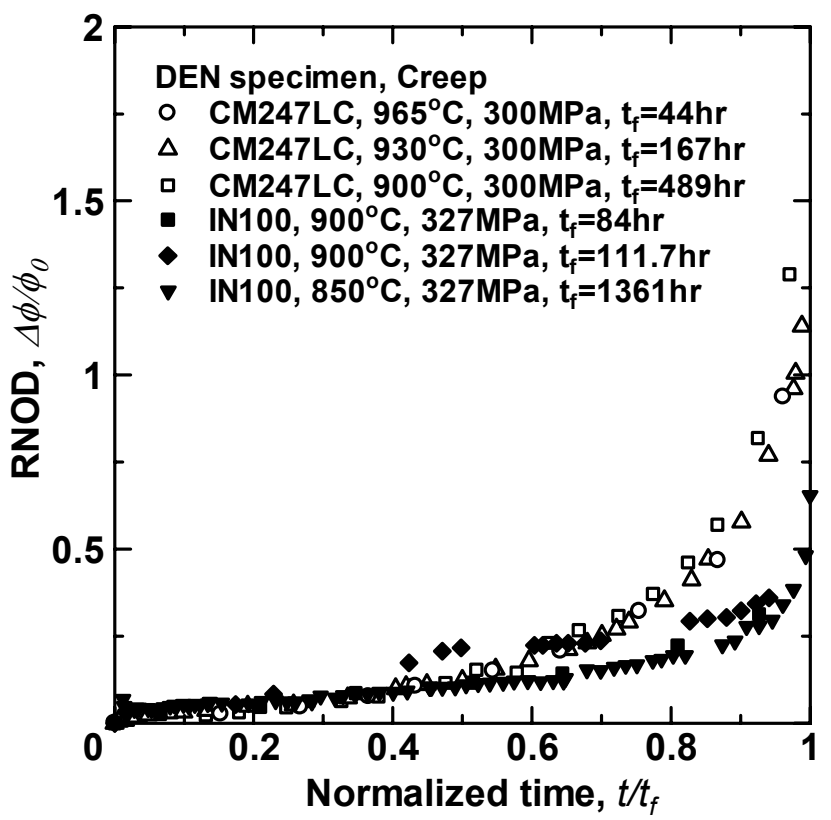

Fig. 3 Characteristics of creep deformation (RNOD). 


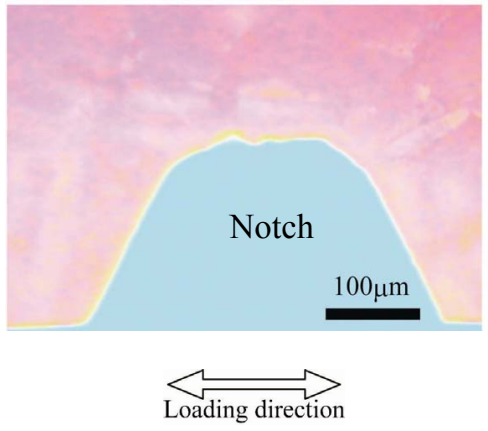

(a) IN100 under the condition of $900^{\circ} \mathrm{C}$, 327MPa. $\left(t / t_{f}=0.46, t_{f}=111.7 \mathrm{hr}\right)$

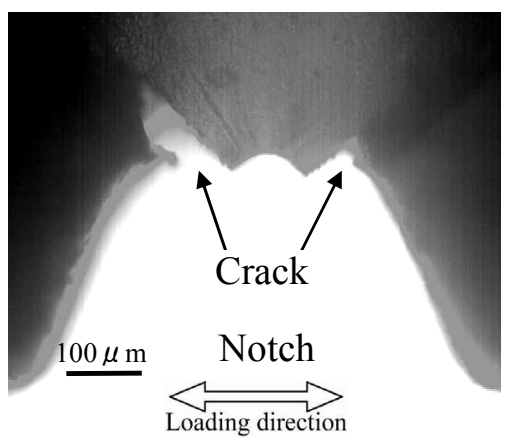

(b) CM247LC under the condition of $930^{\circ} \mathrm{C}$, 300MPa. $\left(t / t_{f}=0.97, t_{f}=167 \mathrm{hr}\right)$

Fig. 4 In-situ observational result around the notch tip.
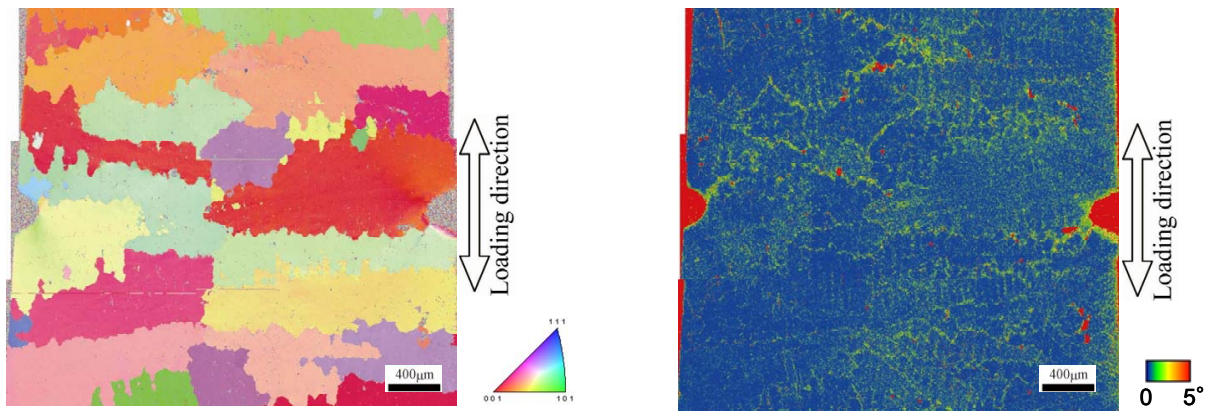

(a) IPF and KAM maps of IN100 at $t / t_{f}=0.46$ under the creep condition of $900^{\circ} \mathrm{C}, 327 \mathrm{MPa}$. $\left(t_{f}=111.7 \mathrm{~h}\right)$
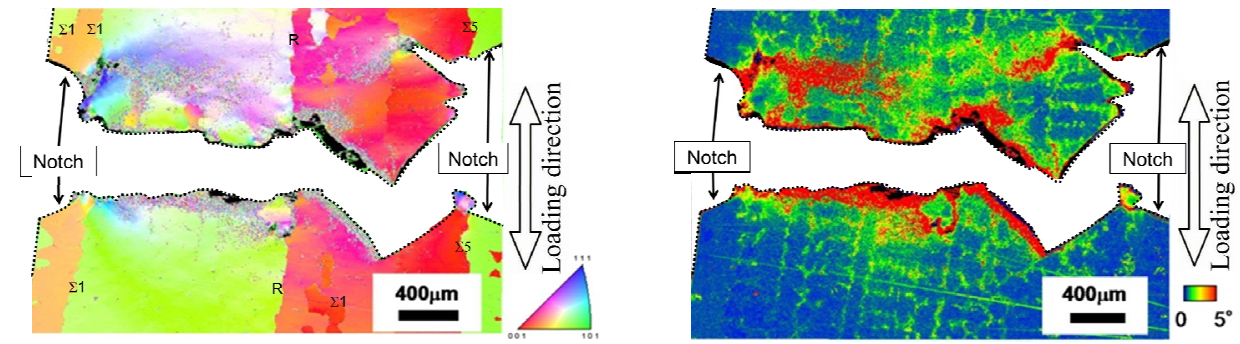

(b) IPF and KAM maps of CM247LC at $t / t_{f}=1.0$ under the creep condition of $930^{\circ} \mathrm{C}$, 300MPa. $\left(t_{f}=167 \mathrm{~h}\right)$

Fig. 5 FE-SEM/EBSD observational results.

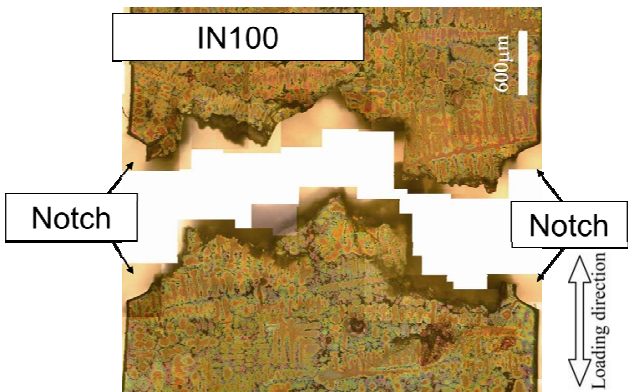

(a) IN100

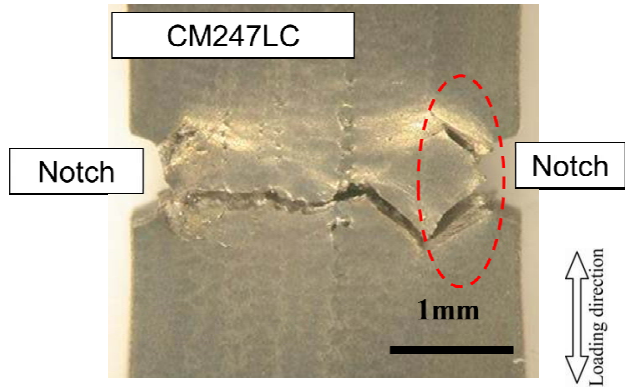

(b) CM247LC

Fig. 6 Creep crack growth path. 


\section{Mechanical analysis of creep damage formation behavior}

\subsection{Finite Element Analysis and Models}

To clarify the creep damage formation behavior for IN100 and CM247LC, the analyses were conducted by using the two-dimensional elastic-plastic creep finite element method which has been developed in the authors' laboratory ${ }^{2)}$. The analytical models for IN100 and CM247LC are shown in Figs. 7 and 8, respectively. The model in Fig. 7 has perpendicular boundaries to the loading direction imitating the grain distribution of IN100 and the model in Fig. 8 has parallel boundaries to the loading direction imitating the grain distribution of CM247LC. Figure 7 represents a half side of DEN specimen including a notch part due to the bilateral symmetry of mechanical properties distribution. Figure 8 represents the center part of the DEN specimen including both notches due to the asymmetrical distribution of mechanical properties. In these models, to imitate the distribution of grain boundaries of IN100 and CM247LC, grains are arranged by two different mechanical properties, such as young's modulus and yield stress, as shown by grain-1 and grain-2 so that the areas which have different mechanical properties located next to each other. Mechanical properties are classified conveniently into the following applications, as shown in Table 4. The mechanical properties of CM247LC at $900{ }^{\circ} \mathrm{C}$ obtained from experimental results ${ }^{23)}$ was used for the values of grain-1 as a substitute for that of IN100 at $900{ }^{\circ} \mathrm{C}$. The different values of mechanical properties used for grain-1 and grain-2 are due to the fact that the angle of crystal orientation to the loading direction affects the mechanical properties. For the single crystal Ni-base superalloy, remarkable elastic and plastic anisotropies exist so that the young's modulus and yield stress have two times different value for each corresponding crystal orientation ${ }^{22}$. For the mechanical properties of CM247LC, the values for grain-1 and grain-2 were determined from the experimental results of CM247LC at $800{ }^{\circ} \mathrm{C}$ and $900{ }^{\circ} \mathrm{C}$, respectively ${ }^{23)}$. The boundaries of mechanical properties are shown as red lines in the figures.

The constitutive laws used in this analysis are shown as eqs. (1) - (4). The characteristic of work-hardening for plastic deformation is approximated by

$$
H^{p}=n C_{1}\left(\alpha+\bar{\varepsilon}_{p}\right)^{n-1}
$$

where $n, C_{l}$ and $\alpha$ are constant values, respectively. $\bar{\varepsilon}_{p}$ is the value of equivalent plastic strain. The Von-Mises criterion is used for yielding condition. After nodes are yielded, they are replaced by creep condition nodes characterized by eqs. (2) and (3). On the basis of Norton's law shown in eq. (2), the creep resistant coefficient for creep deformation is approximated by eq. (3).

$$
\begin{gathered}
\dot{\bar{\varepsilon}}_{p}=A \bar{\sigma}^{n} \\
H^{c}=\frac{d \bar{\sigma}}{d \bar{\varepsilon}_{p}}=\frac{1}{n}\left(\frac{1}{A\left(t+C_{2}\right)}\right)^{\frac{1}{n}} \bar{\varepsilon}_{p}\left(\frac{1}{n}-1\right) \\
\Delta t_{i}=\frac{\Delta \bar{\varepsilon}_{p}}{A \bar{\sigma}^{n}}
\end{gathered}
$$

$H^{c}$ is creep resistant coefficient and $C_{2}$ is the constant value, respectively. The parameter $t$ is the time of creep loading. $A$ and $n$ are the material constants expressed by the Norton's law shown in eq. (2). In this analysis, the creep resistant coefficient is applied to calculate the deformation of the creep region which is changed from the plastic region after the one step of plastic deformation. Therefore, the creep region can be defined in this analysis. The 
values of time increment, $\Delta t_{i}$ are calculated by eq. (4) for creep condition nodes. They are averaged and $\Delta t$ is defined as the mean value of $\Delta t$.

\subsection{Analytical results}

The images of formation of creep region obtained from the model, as depicted in Figs. 7 and 8, are shown in Figs. 9 (a) and (b), respectively. In each figure, the elastic and plastic regions are shown in green and yellow, respectively. Creep regions are indicated by red color and they were calculated from the equivalent stresses.

In Fig. 9 (a), the creep region as shown in red color initiated from the notch tip in the direction of $45^{\circ}$ to the extended notch direction and propagated to the boundaries between the different mechanical properties. This has resulted in the restraint of creep damage propagation around the notch tip. From Fig. 9 (b), the creep region initiated from the notch tip in the direction of $45^{\circ}$ to the extended notch direction and the region becomes larger in the area of softer mechanical properties. At the final stage $t / t_{f}=1.0$, the creep region propagated along the boundary of different mechanical properties which is parallel to the loading direction. This has resulted in the difference of creep crack growth behavior of IN100 and CM247LC due to the effect of the microstructural strengthening. These formations of creep region are found to be in good agreement with the distribution of high KAM value which is related to the creep damage.

Table 4 Material properties for FEM analysis.

\begin{tabular}{|c|c|c|c|c|c|c|c|}
\hline & \multirow{2}{*}{$\begin{array}{c}\mathrm{E} \\
(\mathrm{GPa})\end{array}$} & \multirow[b]{2}{*}{$v$} & \multirow{2}{*}{$\begin{array}{c}\sigma_{\mathrm{Y}} \\
(\mathrm{MPa})\end{array}$} & \multirow{2}{*}{$\begin{array}{c}\mathrm{H}^{\mathrm{P}} \\
(\mathrm{GPa})\end{array}$} & \multicolumn{2}{|c|}{ Norton's law } \\
\hline & & & & & & $\begin{array}{c}\mathrm{A} \\
\left(\mathrm{MPa}^{-n} \mathrm{~h}^{-1}\right)\end{array}$ & $\mathrm{n}$ \\
\hline \multirow{2}{*}{$\begin{array}{l}\text { Model for } \\
\text { IN100 }\end{array}$} & Grain1 & 85.3 & 0.3 & 507.9 & 6.5 & $2.0 \times 10^{-23}$ & 7.0 \\
\hline & Grain2 & 42.65 & 0.3 & 207.9 & 3.5 & $2.0 \times 10^{-23}$ & 7.0 \\
\hline \multirow{2}{*}{$\begin{array}{l}\text { Model for } \\
\text { CM247LC }\end{array}$} & Grain1 & 92.6 & 0.3 & 627.0 & 6.5 & $1.21 \times 10^{-24}$ & 7.7 \\
\hline & Grain2 & 85.3 & 0.3 & 507.9 & 3.5 & $3.52 \times 10^{-14}$ & 4.35 \\
\hline
\end{tabular}

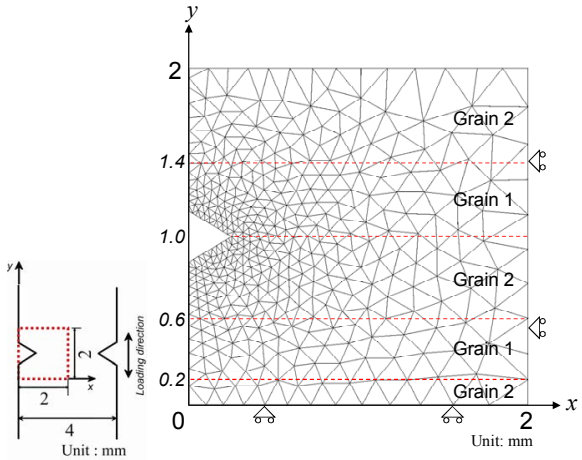

Fig. 7 Analytical model of a DEN specimen with a $\mathrm{V}$ notch as an imitated structure of IN100.

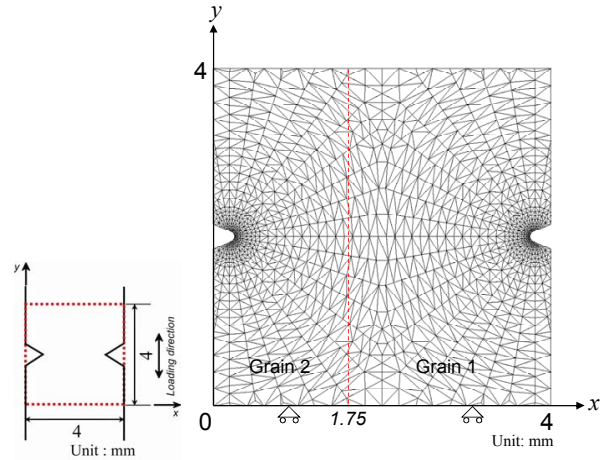

Fig. 8 Analytical model of a DEN specimen with $\mathrm{V}$ notches as an imitated structure of CM247LC 


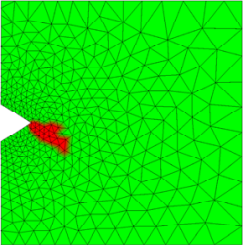

$\mathrm{t} / \mathrm{t}_{\mathrm{f}}=0.74$

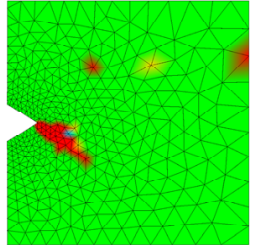

$\mathrm{t} / \mathrm{t}_{\mathrm{f}}=0.76$

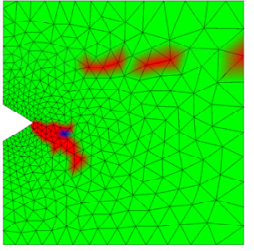

$\mathrm{t} / \mathrm{t}_{\mathrm{f}}=0.78$

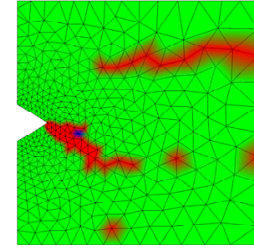

$\mathrm{t} / \mathrm{t}_{\mathrm{f}}=0.82$

(a) Creep region of IN100.

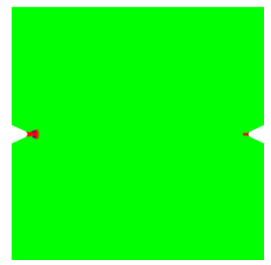

$\mathrm{t} / \mathrm{t}_{\mathrm{f}}=0.6$

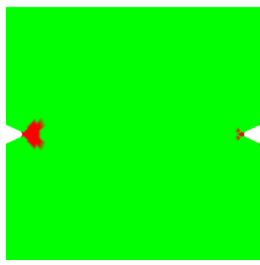

$\mathrm{t} / \mathrm{t}_{\mathrm{f}}=0.8$

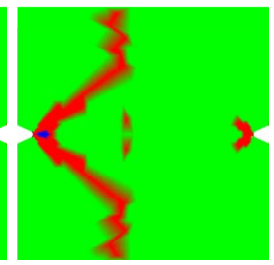

$\mathrm{t} / \mathrm{t}_{\mathrm{f}}=1.0$

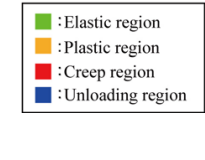

(b) Creep region of CM247LC.

Fig. 9 Analytical results using two-dimensional elastic-plastic creep finite element method based on the designed method to find out creep damage.

\section{Discussion}

The creep damage distribution of IN100 and CM247LC were observed as the distribution of KAM value along the grain boundaries by the EBSD method and the creep damage formation behavior was investigated by the mechanical analysis as the creep region using the FEM analysis. For IN100, it was shown that the creep damage was not observed by the in-situ observational system which is able to capture the damage and crack of $10 \mu \mathrm{m}$ orders and the creep crack rapidly grew after the crack initiation. From these results, the importance of determining the crack initiation and early crack growth by inspecting the micro damage and estimating the behavior of micro damage formation for establishing the law of creep fracture life for brittle material such as IN100 was indicated.

To determine the creep crack initiation life, its criterion was discussed on the experimental characteristics of creep crack growth and the characteristics of load line displacement obtained by the creep crack growth tests using $C(T)$ specimens ${ }^{11,14)}$.

In accordance with the conventional life assessment techniques ${ }^{24)}$, creep crack initiation life is defined as a specific crack length which depends on the specimen geometry and size, such as $500 \mu \mathrm{m}$ for $\mathrm{C}(\mathrm{T})$ specimen. In this paper the criterion of the creep crack initiation life was defined as the time when the length of a crack growth takes the length of $1.0 \mathrm{~mm}$, as shown in Fig. 10, the data scatter was caused approximately $35 \%$ for $\mathrm{C}(\mathrm{T})$ specimens of IN100.

On the other hand, the scatter of the experimental data characterized by the RNOD relation, as an estimating parameter of crack initiation life proposed by the present author ${ }^{25}$, was found to be $25 \%$ if the criterion of the creep crack initiation life was defined as the specific value of $R N O D$, for example 0.034 that is the average $R N O D$ at the point of $t / t_{f}=0.8$ (the starting point of acceleration), as shown in Fig. 11. This RNOD characteristic was found to have correlation with the plastic deformation work $W_{p}$ calculated from the inelastic equivalent strain, which is estimated analytically as shown in Fig. $12^{26)}$. This is the reason why the RNOD characteristic shows unique curve for each material and specimen. Therefore, the criterion of creep crack initiation is not the determination of crack length but the value of $R N O D$ with respect to the creep damage accumulation behavior. 


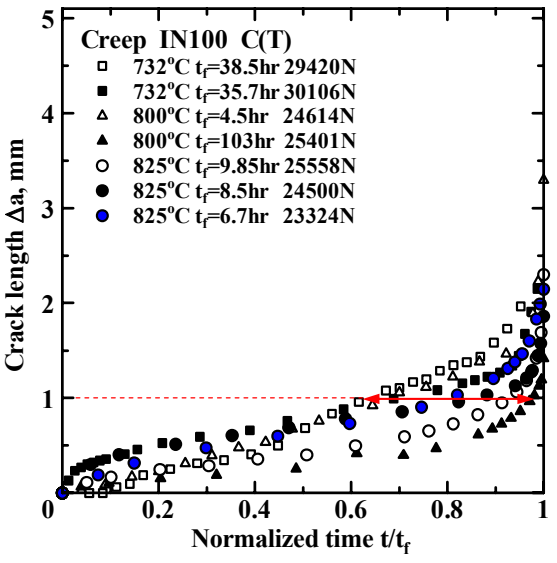

Fig. 10 Characteristics of creep crack growth for IN100 obtained from the experiments $^{11,14)}$.

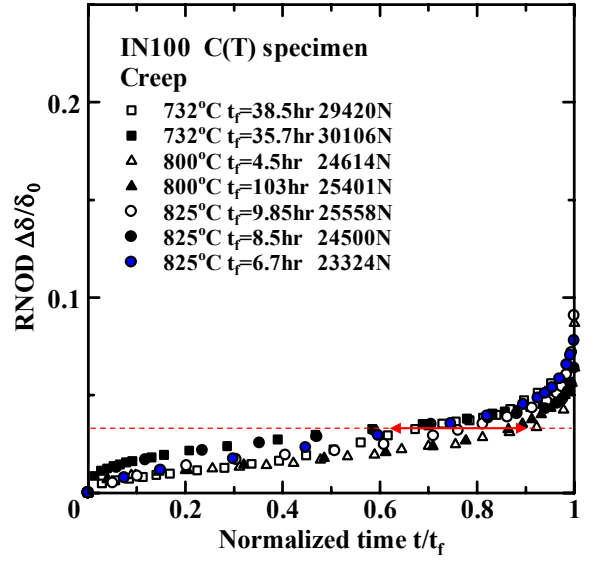

Fig. 11 Characteristics of $R N O D$ for IN100 obtained from the experiments ${ }^{11,14)}$.

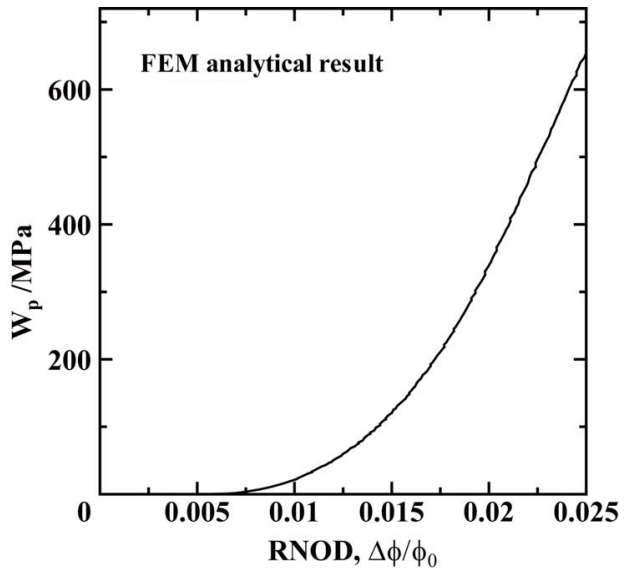

Fig. 12 The relationship between plastic deformation work $W_{p}$ and $R N O D^{26)}$.

\section{Conclusions}

In this study, the creep crack growth tests were performed using in-situ observational testing machine with microscope to observe the creep damage formation and creep crack growth behavior. After the tests, the microstructural observation was conducted using FE-SEM/EBSD on the test specimens. Additionally, the analyses of two-dimensional elastic-plastic creep finite element using the designed method to find out creep damage region were conducted to understand the effect of strengthening mechanism on creep damage formation. The following results were obtained.

(1) The RNOD characteristic of CM247LC was found to be slightly increased as compared with that of IN100 at the final stage of creep deformation due to the occurrence of creep crack growth. However, in the case of IN100, creep damage distributed along the grain boundaries through the specimen width and the crack initiation from the notch tip was not observed which results in the resistance of increasing RNOD. The creep damage formation behaviors observed by EBSD are found to be in good agreement 
with those which were obtained from FEM analysis. Creep damage formation was found to be very sensitive to the distribution of microstructure ahead of the notch tip.

(2) The experimental results mentioned above suggest that it is important to determine the creep crack initiation and early crack growth to predict the life of creep fracture due to the rapid creep crack growth after the crack initiation.

(3) The crack growth behavior is affected by the heterogeneous microstructural distribution; therefore the high accurate prediction of creep fracture life could be realized by using the $R N O D$ characteristic which is corresponding to the amount of the micro creep damage accumulation, that is, the construction of micro damage mechanics.

\section{Acknowledgements}

The authors are grateful to Dr. A. Fuji in IHI Corporation for supply of the material used.

\section{References}

(1) K. Igashira, Creep Damage Evaluation of Ni-base Superalloys for Gas-Turbine by X-ray Diffraction Method, Transactions of the Japan Society of Mechanical Engineers, Series A, Vol. 74, No. 739 (2008), pp.308-314.

(2) H. Takeuchi, A.T. Yokobori, Jr., S. Hosono, D. Kobayashi and K. Sato, Theoretical Analysis of the Effect of Branched-Cracks on the Creep Crack Growth of Advanced Heat-Resistant Materials Based on Finite Element Method Using a Penalty Function, Journal of Japan Institute of Metals, Vol.71, No. 5 (2007), pp.452-457.

(3) J. D. Landes and J. A. Begley, A Fracture Mechanics Approach to Creep Crack Growth, ASTM Spec. Tech. Publ., Vol. 590 (1976), pp.128-148.

(4) K. Ohji, K. Ogura, and S. Kubo, Transactions of Japan Society of Mechanical Engineers, Vol. 44 (1975), pp.1831-1839.

(5) S. Taira, R. Ohtani, and T. Kitamura, Application of J-Integral to High-Temperature Crack Propagation, ASME Journal of Engineering Materials and Technology, Vol. 101 (1979), pp.154-167.

(6) R. Koterazawa and T. Mori, Applicability of Fracture Mechanics Parameters to Crack Propagation Under Creep Condition, ASME Journal of Engineering Materials and Technology, Vol. 99 (1977), pp.298-305.

(7) A. Fuji, and M. Kitagawa, A Comparison of Creep Crack Growth Behavior in Nickel Based Superalloy With Low Alloy Steel, Advances in Fracture and Structural Integrity, Proceedings of ICF 8, V. V. Panasyuk, ed. (1994), pp.487.

(8) B. Dogan, and K. H. Schwalbe, Creep Crack Growth Behavior of Ti-6242, ASTM Symposium, Philadelphia, H. A. Ernst, A. Saxena, and D. L. McDowell, eds., ASTM STP 1131 (1992), pp.284-296.

(9) A. T. Yokobori, Jr. and T. Yokobori, T. Kuriyama, T. Kako, and Y. Kaji, Characterization of High Temperature Creep Crack Growth Rate in Terms of Independent Parameters, Proceedings of the International on Creep, JSME, I Mech E, ASME (1986), pp.135-140.

(10) A. T. Yokobori, Jr. and T. Yokobori, New Concept to Crack Growth at High Temperature Creep and Creep-Fatigue, Advances in Fracture Research, Proceedings of ICF7, K. Salama, K. Ravi-chander, D. M. R. Taplin, and P. Rama Rao, eds., Pergamon, 
New York, Vol. 2 (1989), pp.1723-1735.

(11) A. T. Yokobori, Jr., T. Uesugi, T. Yokobori, T. Fuji, M. Kitagawa, I. Yamaya, M. Tabuchi and K. Yagi, Estimation of Creep Crack Growth Rate in IN-100 Based on the Q* Parameter Concept, Journal of Material Science, Vol. 33 (1998), pp.1555-1562.

(12) L. M. Kachanov, Time of the rupture process under creep condition, Izvestiya Akademii Nauk Sssr Otdelenie Tekhnicheskikh Nauk, No. 8 (1958), pp.26-31.

(13) J. L. Bassani and D.E. Hawk, in Proceedings of MECAMAT, International Seminar on High Temperature Fracture Mechanisms and Mechanics, Dourdan, France, P. Bensussan et al. (eds.) MECAMAT, Moissy-Cramayet (1987), pp.19-40.

(14) M. Tabuchi, K. Kubo, K. Yagi, A. T. Yokobori, Jr. and A. Fuji, Results of a Japanese Round Robin on Creep Crack Growth Evaluation Methods for Ni-base Superalloys, Engineering Fracture Mechanics, Vol. 62 (1999), pp.47-60.

(15) T. Yokobori, H. Sakata and A. T. Yokobori, Jr., Studies on crack growth rate under high temperature creep, fatigue and creep-fatigue interaction-II, Engineering Fracture Mechanics, Vol. 13 (1979), pp.523-532.

(16) A. T. Yokobori, Jr., T. Yokobori, T. Kuriyama and T. Kako, Advances in Fracture Research, Proceedings of ICF 6, Eds: S. R. Valluri, et al., Pergamon Press (1984), pp.2181.

(17) M. Kamaya, "Measurement of Plastic Strain Distribution by Electron Backscatter Diffraction", Journal of the Society of Materials Science, Japan, Vol. 58, No. 7 (2009) pp.568-574.

(18) H. Kimura, Y. Wang, Y. Akiniwa and K. Tanaka, "Misorientation Analysis of Plastic Deformation of Austenitic Stainless Steel by EBSD and X-Ray Diffraction Methods", Transactions of the Japan Society of Mechanical Engineers, Series A, Vol. 71, No. 712 (2005) pp.1722-1728.

(19) T. Yokomaku, R. Yoda, Inspection Technology, Vol. 12, No. 1 (2007) pp. 36-41.

(20) R. Takaku, D. Saito, Y. Yoshioka, "Effect of Grain Size and Crystal Orientation on Creep Damage Evaluation by Changes of Misorientation in Hastelloy X", Journal of the Society of Materials Science, Japan, Vol. 58, No. 3 (2009) pp. 229-234.

(21) Y. Sakakibara, K. Kubushiro, G. Nakayama, "Distribution of Misorientation at Grain Boundary by EBSD for Low Carbon Stainless Steel Strained by Various Deformation Modes", J. Japan Inst. Metals, Vol. 74, No. 4 (2010) pp. 258-263.

(22) M. McLean: Directionally Solidified Materials for High Temperature Service, The Metals Society, London, 1983.

(23) M. Yamamoto, M. Yaguchi and T. Ogata, Central Research Institute of Electric Power Industry (2000) Research Paper: T99024. (In Japanese)

(24) B. Dogan, U. Ceyhan, B. Petrovski, High temperature crack initiation and defect assessment of P22 steel weldments using time dependent failure assessment method Engineering Fracture Mechanics, Vol. 74, Issue 6 (2007), pp.839-852.

(25) A. T. Yokobori, Jr. and T. Yokobori, THE CRACK INITIATION AND GROWTH UNDER HIGH TEMPERATURE CREEP, FATIGUE AND CREEP-FATIGUE MULTIPLICATION, Engineering Fracture Mechanics, Vol. 31, No. 6 (1988), pp.931-945.

(26) Y. Nagumo, A. T. Yokobori, Jr., R. Sugiura, T. Matsuzaki, H. Takeuchi and Y. Ito, Behavior of Branch Cracking and the Microstructural Strengthening Mechanism of Polycrystalline Ni-Base Superalloy, IN100 under Creep Condition, Materials Transactions, Vol. 52, No. 10 (2011), pp.1876-1884. 